\title{
Treatment of depersonalization disorder with fluoxetine: a case
} report

\author{
Michalis Saitis*, Konstantinos Katsigiannopoulos and Georgios Papazisis
}

Address: Community Mental Health Center of N/W District, Thessaloniki, Greece

* Corresponding author

from International Society on Brain and Behaviour: 3rd International Congress on Brain and Behaviour

Thessaloniki, Greece. 28 November - 2 December 2007

Published: 17 April 2008

Annals of General Psychiatry 2008, 7(SuppI I):S208 doi:I0.1 I86/I744-859X-7-SI-S208

This abstract is available from: http://www.annals-general-psychiatry.com/content/7/SI/S208

(c) 2008 Saitis et al.; licensee BioMed Central Ltd.

\section{Background}

One small prospective series and two single case reports had described successful treatment of primary depersonalization disorder in a number of patients treated with fluoxetine [1-3]. But then, one recent randomized, double masked, placebo-controlled trial failed to show efficacy [4]. We present the case of depersonalization disorder that responded favorably to fluoxetine treatment.

\section{Materials and methods}

A 23-year old single man had a 1-year history of primary depersonalization disorder. He described feeling "detached from my body, as if I was observing myself from the outside, cut off from emotions and feelings, feeling as if I had completely lost my self and feeling like I was in a dream". He felt far removed from everything. The patient was treated with fluoxetine $10 \mathrm{mg} /$ day, which was slowly raised to $40 \mathrm{mg} /$ day.

\section{Results}

Eight weeks after beginning fluoxetine, the patient had a remarkable improvement. Following complete resolution of the depersonalization symptoms, the patient began to socialize, entertain and work. This is continued for 12 months of follow up.

\section{Conclusions}

Fluoxetine may be a promising pharmacological treatment for primary depersonalization disorder.

\section{References}

I. Hollander E, Liebowitz MR, DeCaria C, Fairbanks J, Fallon B, Klein DF: Treatment of depersonalization with serotonin reuptake blockers. J Clin Psychopharmacol I990, I 0(3):200-3. Jun

2. Fichtner CG, Horevitz RP, Braun BG: Fluoxetine in depersonalization disorder. Am J Psychiatry 1992, I 49( I 2): I750-I. Dec

3. Ratliff NB, Kerski D: Depersonalization treated with fluoxetine. Am J Psychiatry 1995, I 52(I I): 1689-90. Nov

4. Simeon D, Guralnik O, Schmeidler J, Knutelska M: Fluoxetine therapy in depersonalisation disorder: randomised controlled trial. BrJ Psychiatry 2004, 185:3I-6. Jul 